\title{
ЭМОЦИОНАЛЬНОЕ ВЫГОРАНИЕ СОТРУДНИКОВ СОВРЕМЕННОЙ ОРГАНИЗАЦИИ: ДИАГНОСТИКА И ПРОФИЛАКТИКА
}

\section{EMOTIONAL BURNOUT OF EMPLOYEES IN A MODERN ORGANIZATION: DIAGNOSTICS AND PREVENTION}

\section{E. Akhmetgalieva}

Summary: The article is devoted to the study of the phenomenon of emotional burnout of employees of a modern organization. The article considers the key tools for identifying the burnout syndrome, describes its characteristic signs and symptoms, and offers modern methods for preventing and overcoming the above-mentioned syndrome.

The main method used in writing the article is a review; special attention is paid to the development of ideas of foreign and domestic scientists about the nature of emotional burnout.

As a result of writing the article, it was determined that emotional burnout has negative consequences both for employees, manifested in the deterioration of their physical health, reduced motivation to work, and for organizations, contributing to an increase in staff turnover, reducing labor productivity. The main tools for diagnosing and detecting emotional burnout are combined surveys and interviews, which can be used to assess the severity of the syndrome. Based on the study of the factors of emotional burnout, it is established that the development of this syndrome is influenced by both intrapersonal and organizational aspects. Prevention of emotional burnout involves both purely individual work, and a set of organizational measures related to the optimization of labor processes, the development of staff training programs, and the introduction of psychological support practices. A modern trend is the formation of Wellbeing programs.

Keywords: emotional burnout, professional deformation, prevention, diagnosis, symptoms, staff, employees.

\author{
Ахметгалиева Эльвира Ильшатовна \\ Российский экономический университет \\ им. Г.В. Плеханова \\ elviraahmetgalieva@gmail.com
}

Аннотация: Статья посвящена изучению феномена эмоционального выгорания сотрудников современной организации. В материале рассмотрены ключевые инструменты выявления синдрома эмоционального выгорания, описаны его характерные признаки и симптомы, а также предложены современные методы профилактики и преодоления вышеназванного синдрома. Основным методом, используемым при написании статьи, является обзор; особое внимание уделяется развитию представлений зарубежных и отечественных ученых о природе эмоционального выгорания.

В результате написания статьи было определено, что эмоциональное выгорание влечет негативные последствия как для сотрудников, проявляясь в ухудшении их физического здоровья, снижения мотивации к трудовой деятельности, так и для организаций, способствуя росту текучести персонала, сокращению производительности труда. Основными инструментами диагностики и выявления эмоционального выгорания являются комбинированные опросы и интервью, с помощью которых возможна оценка степени выраженности синдрома. На основе изучения факторов возникновения эмоционального выгорания установлено, что на развитие данного синдрома оказывают внимание как внутриличностные, так и организационными аспекты. Профилактика эмоционального выгорания подразумевает как сугубо индивидуальную работу, так и комплекс организационных мер, связанных с оптимизацией трудовых процессов, развитием программ обучения персонала, внедрением практик психологической поддержки. Современным трендом является формирование Wellbeing-программ.

Ключевые слова: эмоциональное выгорание, профессиональная деформация, профилактика, диагностика, симптомы, персонал, сотрудники.

учный и практический интерес к проблеме эмоционального выгорания сотрудников.

Термин «эмоциональное выгорание» был впервые использован американским психологом Х.Дж. Фройденбергером (1974), который ввел данное понятие в обиход для характеристики психологического состояния профессионалов, находящихся, в связи со спецификой своей деятельности, в постоянном и интенсивном взаимодействии с людьми, подвергаясь эмоциональному перенапряжению. Эмоциональное выгорание неформально называлось «платой за сочувствие», поскольку наиболее часто оно возникало у врачей, полицейских, учителей [8].

Дальнейшие исследования позволили значительно 
расширить понимание синдрома эмоционального выгорания.

А. Пайнс и А. Аронсон (1988) отметили, что эмоциональное выгорание как состояние когнитивного и физического истощения вызывается длительным пребыванием в «эмоционально перегруженных» ситуациях, выдвинув предположение, что эмоциональному выгоранию подвержены представители абсолютно разных, а не только социальных, профессий [4].

Важный вклад в понимание специфики эмоционального выгорания внесла К. Маслач, разработав при участии С. Джексона трехфакторную модель синдрома эмоционального выгорания. Ученые выделили три проявления выгорания: эмоциональное истощение (сниженный эмоциональный фон), деперсонализация (заметные деформации в отношениях с другими людьми, негативизм) и редукция профессиональных достижений (тенденция к негативной оценке личных качеств и достижений).

Отечественный исследователь В.В. Бойко предложил теорию о том, что эмоциональное выгорание представляет собой механизм психологической защиты, проявляющейся в полном или частичном отвержении эмоций в ответ на травмирующее воздействие, и впоследствии создал и апробировал методику диагностики степени выраженности синдрома эмоционального выгорания [1].

Синдром эмоционального выгорания проявляется в целом комплексе физиологических и эмоциональных симптомов. Работники начинают испытывать проблемы со здоровьем, у них нарушается сон, проявляются изменения аппетита. Постоянное чувство усталости негативно сказывается на работоспособности; нарушения сна влекут за собой снижение внимательности и, как следствие, повышение частоты ошибок в выполнении профессиональных задач. Впоследствии у сотрудника возникают негативные установки к рабочим обязанностям, а также к коллективу.

В трудах В.Е. Орел также описаны влияние эмоционального выгорания сотрудников на показатели деятельности организации:

- текучесть кадров;

- нарастание враждебности среди сотрудников, и, как следствие, возникновение конфликтов;

- неудовлетворенность трудовой деятельностью;

- сокращение производительности труда;

- снижение инициативности у сотрудников [3].

Что касается причин возникновения эмоционального выгорания, то можно выделить несколько групп факторов, а именно: внутриличностных и организационных
К личностным факторам можно отнести склад характера человека; его психотип; темперамент; уровень развития эмоционального интеллекта. Стрессоустойчивость и реакция сотрудника на стресс-факторы и раздражители также оказывает прямое влияние на подверженность эмоциональному выгоранию. Можно отметить также такой фактор, как локус контроля. Сотрудники с интернальным локусом контроля склонны к самоанализу, саморефлексии; они более уравновешены и коммуникабельны. Сотрудники с экстернальным локусом, напротив, неуверенны в себе, тревожны; склонны откладывать принятие важных решений на неопределенный срок. Экстерналы в большей степени подвержены возникновению эмоционального выгорания.

Организационные факторы характеризуют условия рабочей среды, содержание работы, социально-психологический климат в коллективе. К организационным составляющим, приводящим к возникновению эмоционального выгорания, можно отнести:

1. Ненормированный рабочий график, регулярные переработки в условиях, требующих высокой производительности;

2. Ролевые конфликты и ролевую неопределенность, возникающие в результате непрозрачного и неравномерного распределения задач между исполнителями рабочего процесса.

3. Отсутствие адекватной оценки со стороны руководства;

4. Монотонность и рутинность работы;

5. Физическое изнеможение, отсутствие возможностей для отдыха;

6. Отсутствие перспектив дальнейшего личностного и карьерного роста;

7. Неграмотно выстроенная система адаптации и наставничества в организации;

8. Эмоционально и когнитивно сложные коммуникации.

Важность своевременной диагностики и профилактики выгорания подтверждается результатами исследований. Так, по данным Института Гэллапа, сотрудники, испытывающие эмоциональное выгорание, на 63\% чаще других сотрудников берут больничный, на 23\% чаще обращаются в неотложную помощь, в 3 раза чаще увольняются [7].

При рассмотрении способов диагностики эмоционального выгорания следует отметить широкий инструментарий, включающий в себя опросы, беседы, анкетирование сотрудников.

К наиболее популярным методам диагностики синдрома эмоционального выгорания можно отнести методику диагностики уровня эмоционального выгорания В.В. Бойко, позволяющий определить стадию эмоцио- 
нального выгорания; опросник «Эмоциональное выгорание», составленный К. Маслач и С. Джексон в адаптации Н.Е. Водопьяновой.

С помощью методики диагностики синдрома эмоционального выгорания, разработанной В.В. Бойко, можно определить наличие характерных симптомов эмоционального выгорания и, при наличии такового, определить стадию эмоционального выгорания: «напряжения», «резистенции» или «истощения». Тест, используемый в рамках данной методики, состоит из 84 вопросов, каждый из которых характеризуется определенным количеством баллов, что, в результате последующих подсчетов, может дать достаточно полное описание психоэмоционального состояния респондента.

Опросник «Эмоциональное выгорание» (MBI) был создан на основе трехфакторной модели К. Маслач и С. Джексон для определения стадии «эмоционального истощения», «деперсонализации», «редукции профессиональных достижений». Сам тест представляет собой набор высказываний, характеризующих эмоции, переживания и чувства респондента, связанные с профессиональной деятельностью. Каждое высказывание необходимо проранжировать в зависимости от частоты наблюдения описанного признака у респондента. Существуют разные адаптации теста в зависимости от пола, гендера или профессиональной категории опрашиваемого [2].

При комплексной оценке выраженности эмоционального выгорания зачастую оценивается уровень профессионального стресса, испытываемого сотрудниками. В качестве примера можно привести Шкалу Лемура-Тесье-Филиона (или шкалу PSM) для оценки структуры переживаемого профессионального стресса. Прохождение опроса по шкале PSM подразумевает оценку утверждений-характеристик психоэмоционального состояния человека за текущую неделю по восьмибалльной шкале. После чего подсчитывается сумма баллов и, соответственно, чем выше полученная сумма, тем сильнее уровень психологического стресса. Низкий уровень стресса свидетельствует об устойчивости индивида к профессиональным нагрузкам и его психологической адаптированности.

Диагностика уровня эмоционального выгорания необходима для нивелирования негативных последствий данного синдрома.

Эффективность мероприятий профилактики выгорания во многом определяется как индивидуальными способностями сотрудников, так и организационными мероприятиями.

Профилактика эмоционального выгорания со сторо- ны сотрудника зиждется на следующих важных фактоpax:

- формирование позитивного отношения к карьере путем изменения негативной установки по отношению к личной и профессиональной жизни;

- овладение приемам релаксации, ауторегуляции;

- регулярное обучение и развитие как профессиональных, так и личностных компетенций, позволяющих активно осваивать современные тенденции в профессии, выстраивать карьерный путь, регулярно общаться с коллегами и представителями смежных профессий;

- ведение здорового образа жизни, регулярные занятия спортом;

- изучение путей преодоления стрессовых ситуаций, стресс-менеджмент;

- использование регулярных перерывов в течение рабочего дня позволит лучше адаптироваться к стрессами обеспечивать психологическую разгрузку;

- адекватное распределение рабочих обязанностей и планирование задач.

Со стороны работодателя важным шагом в решении проблемы эмоционального выгорания является грамотная организация рабочих процессов, обеспечение безопасности на рабочем месте, использование принципов гигиены труда. Целесообразно также практическое применений рекомендаций ВОЗ о поддержании психического здоровья на рабочем месте [8]. Немаловажным фактором является повышение грамотности сотрудников в сфере психического здоровья, а также предотвращение стигматизации психологических проблем. Следующим шагом является коррекция организационной культуры, укрепление психического здоровья посредством развития позитивных аспектов труда и поддержанием сильных сторон сотрудников. Кроме вышеобозначенных направлений деятельности, возможны следующие мероприятия:

- Создание и совершенствование системы обратной связи для нивелирования коммуникативных барьеров между сотрудниками и менеджментом, организация регулярных встреч и открытых обсуждений;

- Привлечение сотрудников к принятию управленческих решений, касающихся, например, оптимизации тех или иных бизнес-процессов;

- Использование командных форм организации рабочих процессов.

При изучении современных тенденций в сфере поддержки физического и психологического здоровья сотрудников, можно отметить возрастающее внимание работодателей к инициативам по охране физического и психологического здоровья сотрудников, их финансового благополучия. Благополучие сотрудника за- 
трагивает такие составляющие, как: психологическую, эмоциональную, физическую. Некоторые современные компании реализуют так называемые Wellbeing программы, или программы поддержки благополучия сотрудников [6]. В рамках подобных программ возможна реализация проектов по поддержке и укреплению физического здоровья сотрудников; их психологического и эмоционального здоровья; их развития и обучения. Возможные направления Wellbeing программы, с учетом вышеобозначенных составляющих комплексного благополучия сотрудников, включают внедрение практики медицинских осмотров, корпоративные фитнеспрограммы, регулярные марафоны и конкурсы, консультации специалистов, тематические «Дни здоровья»; тренинги личностного и профессионального роста, различные семинары по стресс-менеджменту и работе с психоэмоциональным состоянием, а также мероприятия по повышению финансовой грамотности сотрудников. Различные тренинги и семинары повысят осведомлен- ность сотрудников о различных способах диагностики и снижения стресса как одной из причин эмоционального выгорания, сплотят коллектив. Подобные мероприятия способны повысить вовлеченность сотрудников; их мотивацию, что положительно скажется на имидже работодателя.

Таким образом, эмоциональное выгорание сотрудников в настоящее время является серьезной проблемой, влияющей на эффективность деятельности сотрудников и, исходя из этого, требующей качественной диагностики и профилактики. Существует множество инструментов выявления синдрома эмоционального выгорания, профилактика которого, в свою очередь, невозможна без усилий как самого сотрудника, так и работодателя. Комплексным инструментом, применимым и в приложении к проблеме эмоционального выгорания, является формирование Wellbeing-программ, или так называемых программ благополучия сотрудников, затрагивающих важнейшие сферы их жизни.

1. Бойко В.В. Энергия эмоций. Взгляд на себя и других. - СПб.: Питер, 2004

2. Водопьянова Н.Е., Старченкова Е.С. Синдром выгорания: диагностика и профилактика. 2 - изд. - СПб.: Питер, 2009

3. Орел В.Е. Феномен «выгорания» в зарубежной психологии: эмпирические исследования / В. Е. Орел // Журнал практической психологии и психоанализа. $-2001 .-$ № 3.

4. Слободчиков И.М., Молокоедов А.В., Удовик С.В. Эмоциональное выгорание в профессиональной деятельности - М.: Левъ, 2018. - 252 с.

5. Чутко Л. С. Синдром эмоционального выгорания. Клинические и психологические аспекты / Л. С. Чутко. - 2- ое изд-ие. - М. :МЕДпресс-информ, 2015. 255 c.

6. Экгард Е. Программа Wellbeing (Здоровье и благополучие) в Unilever / Экгард Е. // Льготы и Бенефиты. - 2019. - №4. - с.3-6

7. Employee Burnout, Part 1: The 5 Main Causes [Электронный ресурс]: https://www.gallup.com/workplace/237059/employee-burnout-part-main-causes.aspx

8. Freudenberger H. North G. (1992): Burn-out bei Frauen. Frankfurt, $2^{\circ}$.

9. Workplace mental health: developing an integrated intervention approach [Электронный ресурс]: https://bmcpsychiatry.biomedcentral.com/ articles/10.1186/1471-244X-14-131 